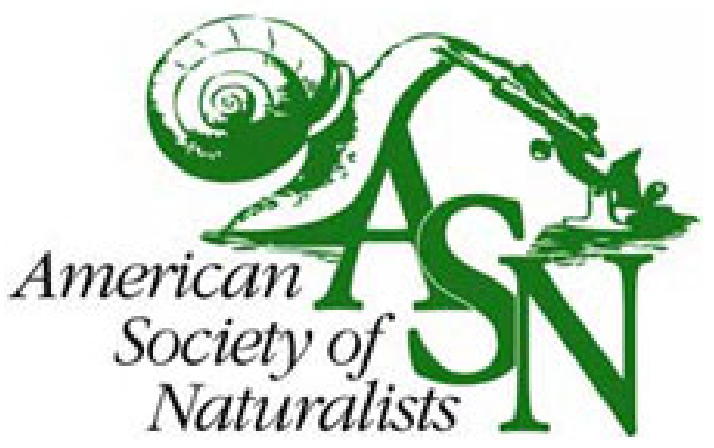

Evaluating the Efficacy of Entomopathogenic Nematodes for the Biological Control of Crop Pests: A Nonequilibrium Approach.

Author(s): A. Fenton, R. Norman, J. P. Fairbairn, and P. J. Hudson

Reviewed work(s):

Source: The American Naturalist, Vol. 158, No. 4 (October 2001), pp. 408-425

Published by: The University of Chicago Press for The American Society of Naturalists

Stable URL: http://www.jstor.org/stable/10.1086/321993

Accessed: 08/06/2012 09:33

Your use of the JSTOR archive indicates your acceptance of the Terms \& Conditions of Use, available at http://www.jstor.org/page/info/about/policies/terms.jsp

JSTOR is a not-for-profit service that helps scholars, researchers, and students discover, use, and build upon a wide range of content in a trusted digital archive. We use information technology and tools to increase productivity and facilitate new forms of scholarship. For more information about JSTOR, please contact support@ jstor.org. 


\title{
Evaluating the Efficacy of Entomopathogenic Nematodes for the Biological Control of Crop Pests: A Nonequilibrium Approach
}

\author{
A. Fenton, ${ }^{*}$ R. Norman, ${ }^{\dagger}$ J. P. Fairbairn, ${ }^{\ddagger}$ and P. J. Hudson ${ }^{\S}$
}

Institute of Biological Science, University of Stirling, Stirling, Scotland FK9 4LA, United Kingdom

Submitted August 22, 2000; Accepted May 18, 2001

ABSTRACT: The efficacy of entomopathogenic nematodes for biological control is assessed using deterministic models. Typically, the examination of such models involves stability analyses to determine the long-term persistence of control. However, in agricultural systems, control is often needed within a single season. Hence, the transient dynamics of the systems were assessed under specific, shortterm control scenarios using stage-structured models. Analyses suggest that preemptive application may be the optimum strategy if nematode mortality rates are low; applying before pest invasion can result in greater control than applying afterward. In addition, repeated applications will suppress a pest, providing the application rate exceeds a threshold. However, the period between applications affects control success, so the economic injury level of the crop and the life history of the pest should be evaluated before deciding the strategy. In all scenarios, the most important parameter influencing control is the transmission rate. These findings are applicable to more traditional biological control agents (e.g., microparasites and parasitoids), and we recommend the approach adopted here when considering their practical use. It is concluded that it is essential to consider the specific crop and pest characteristics and the definition of control success before selecting the appropriate control strategy.

Keywords: biological control, entomopathogenic nematodes, insect pathogen, nonequilibrium analysis, transient dynamics, models of intermediate complexity.

Over the past $30 \mathrm{yr}$, there has built up a vast literature describing the use of models as tools to evaluate the success

\footnotetext{
* E-mail: acf1@stir.ac.uk.

† E-mail: ran1@stir.ac.uk.

" E-mail: jpf2@stir.ac.uk.

${ }^{\S}$ E-mail: pjh1@stir.ac.uk.
}

Am. Nat. 2001. Vol. 158, pp. 408-425. (c) 2001 by The University of Chicago. 0003-0147/2001/15804-0007\$03.00. All rights reserved. of parasites (broadly defined here to include viruses, bacteria, and parasitoids) as biological control agents of insect pests. The first generation of models was due to the seminal work of Anderson and May, who used simple analytical models to describe the changes in abundance of pest and pathogen and evaluate the long-term stability of the interaction (Anderson and May 1978, 1981; May and Anderson 1978). Subsequently, many workers have made a variety of modifications in an attempt to increase the biological realism and determine the mechanisms leading to stability of the system (Godfray and Waage 1991; Hochberg and Waage 1991; Begon and Bowers 1994; Moerbeek and van den Bosch 1997).

One aspect that has received considerable attention in the last $10 \mathrm{yr}$ is the incorporation of explicit stage structuring in the insect-host population (Murdoch et al. 1987; Godfray and Waage 1991; Briggs and Godfray 1995a, 1995b; Murdoch and Briggs 1996). Such stage structuring, in the form of coupled delay-differential equations, enables greater biological detail to be described by a few, intuitively defined parameters while maintaining a degree of analytical tractability.

However, despite the increased realism of this new generation of models, it may be that, at least in terms of evaluating biological control success, they are not being used to address the pertinent questions. In recent years, a number of authors have drawn attention to the fact that long-term stability rarely has any bearing on the practical success of a control program (Murdoch et al. 1985; Kareiva 1990; Hastings 1999), although the vast majority of models continue to evaluate control success in these terms. We contend that such models of "intermediate complexity" can be used to answer specific, practical questions concerning biological control while retaining many of the generalities that make them attractive in the first place.

While we wish to explore the general importance of transients in developing biological control strategies, in this article, we will specifically consider the use of entomopathogenic nematodes belonging to the family Steiner- 
nematidae (Nematoda: Rhabditida). Entomopathogenic nematodes are lethal obligate parasites of a wide range of invertebrate species, exhibiting many characteristics that make them ideal candidates as biological control agents of insect crop pests, although, to date, they are used in relatively few crop systems (Kaya 1993; Kaya and Gaugler 1993; Peters 1996). In the majority of cases, they are used as short-term, inundative biological control agents, where they are applied in large numbers in response to a perceived pest attack, in the hope that they can bring about a rapid and severe decline in pest numbers (e.g., Grewal and Richardson 1993; Downing 1994; Rinker et al. 1995). As with many other biological control agents, the practical use of entomopathogenic nematodes, at present, is often based more on trial and error than on a firm, ecological understanding (Kareiva 1990; Georgis and Gaugler 1991).

Crucially, for the purposes of this work, entomopathogenic nematodes occupy a unique position in parasite classification, sharing many similarities with the other, more traditional parasite groups (Hudson and Norman 1995). Their massive reproductive potential, whereby hundreds of thousands of nematodes emerge from a single host, suggests they have much in common with microparasites. In contrast, they share an important characteristic with many macroparasites in that they have a freeliving infective stage, which actively seeks out new hosts. Finally, host death is an absolute requirement for successful development; a trait they share with parasitoids. As such, entomopathogenic nematodes can be thought of as a generalizable model, allowing insight into other hostpathogen systems. Hence, much of what follows can easily be extrapolated to consider microparasites and parasitoids.

In a previous article, we used a simple, generic model to explore the use of these nematodes in biological control (Fenton et al. 2000). The analyses suggested that the inability of nematodes to persist as control agents might be due to severe instabilities inherent in the system. However, the success of control can be gauged in various ways and is not simply measured by long-term persistence of pest suppression; it is also important to consider the rate and degree of suppression in response to different timings and rates of application. Hence, the nematodes may prove to be effective control agents if the timing and rates of application can be chosen strategically with the requirements of the particular crop-pest system in mind.

The aim of this article is to use models of intermediate complexity and, through a combination of analytical and simulation techniques, evaluate the use of these nematodes as biological control agents under a number of short-term control scenarios. Specifically, we will assess these nematodes according to the following questions: Can entomopathogenic nematodes be applied in a single, inundative dose following pest invasion to achieve immediate suppression of the pest population (biopesticide)? Can entomopathogenic nematodes be strategically applied in a preemptive manner to prevent invasion of an expected pest attack? Can entomopathogenic nematodes be applied at a constant rate to maintain suppression of a pest population? Through this analysis, we will consider what is the optimum method of nematode application for a number of specific crop-pest systems and also what are the appropriate criteria for assessing biological control success in similar population models.

\section{Methods}

The literature contains a number of published descriptions of the nematode life cycle (Kaya 1993; Smart 1995; Ehlers 1996). Briefly, entomopathogenic nematodes typically inhabit the top $5 \mathrm{~cm}$ of soil, infecting susceptible hosts by means of a free-living dauer larva or infective juvenile. Infection typically occurs through natural openings (mouth, spiracles, anus), and once inside the host's hemocoel, the nematodes liberate a symbiotic bacteria that they carry within the lumen of their gut. The bacteria multiply within the host and digest its body tissues, which results in the death of the host within $48 \mathrm{~h}$ postinfection. The nematodes feed on the resulting nutrient-rich soup, develop into adults, mate, and produce progeny. The nematodes pass through three or four generations inside the host until, approximately $2 \mathrm{wk}$ later, resources become limited and the host lyses, releasing hundreds of thousands of nematodes into the environment.

The original analysis by Fenton et al. (2000) described this life cycle by means of a simple susceptible-infected model, in which the pest and nematode populations were assumed to have continuous, overlapping generations. However, in this article, we are dealing specifically with short-term control, so the highly generalized model may mean that important transient dynamics of the system are lost. To improve the realism of the predictions, we use a modified version of the model to incorporate stage structure in the form of a system of delay-differential equations, explicitly describing the pest larval and adult life cycle stages. Such models are now widely adopted to describe systems where stage structuring is important in influencing the dynamics of the system (Murdoch et al. 1987; Godfray and Waage 1991; Briggs and Godfray 1996; Bonsall et al. 1999).

For our stage-structured model, we divide the pest life cycle into separate stages where the vital parameters (e.g., mortality rates) are assumed to be constant within a stage. We divide our generic pest life cycle into two stages, a "larval stage" (L; defined here to include all preadult instars) and an "adult stage" (A; fig. 1). For simplicity, egg and pupal stages are assumed either to be of insignificant 


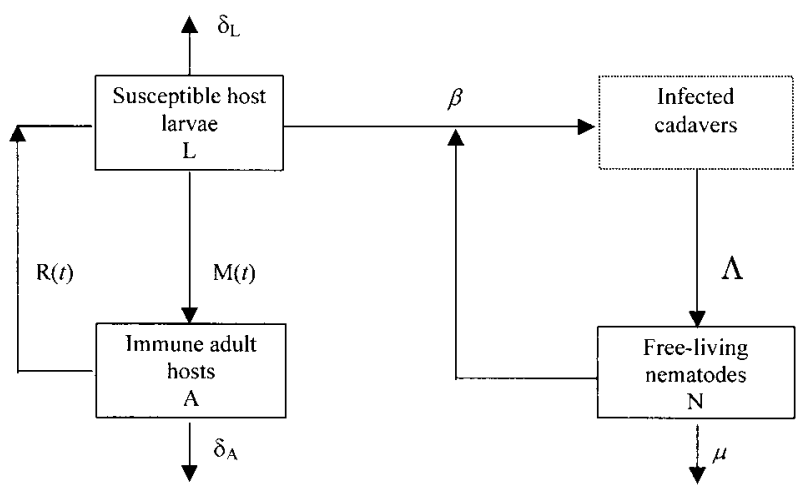

Figure 1: Schematic diagram of the stage-structured, entomopathogenic nematode-host population model. The infected cadaver class is implicit in the model, lasting for duration $T_{\mathrm{I}}$ days. See table 1 for details of all notation.

duration or not to differ in vital characteristics from the larval stage. Such explicit stage structuring enables us to include one important feature of the systems under consideration here; that is, only the larval stage of the pest inhabits the substrate where the nematodes are applied. Hence, in the model, only the larval stage of the pest is susceptible to nematode attack. The model is described fully in appendix A, and all parameter definitions are shown in table 1 .

\section{A Case Study: Control of the Mushroom Fly Lycoriella spp. by Entomopathogenic Nematodes}

To illustrate the applicability of the model, we consider a pest against which entomopathogenic nematodes are currently used for control: sciarid flies (Diptera: Sciaridae), which are major pests of cultivated mushroom (Agaricus bisporus) houses around the world. Fly larvae feed on the compost, breaking it down and preventing mycelial colonization, which results in reduced yields of mushrooms and renders the mushrooms unmarketable (Grewal and Richardson 1993; Rinker et al. 1995). Due to the short life span of crops (typically $8 \mathrm{wk}$ ), long-term persistent control is irrelevant. Hence, nematodes are used for short-term inundative control (Rinker et al. 1995). The economic threshold for mushrooms is very low (Scheepmaker et al. 1997), so control strategies need to be highly effective; it is here that models can play an important role in determining the optimum method of control.

Based on cultures held in our laboratory, we have previously estimated a number of life-history parameters of sciarids. It takes approximately $30 \mathrm{~d}$ from egg to egg at $21^{\circ} \mathrm{C}$, with $20 \mathrm{~d}$ spent in the preadult stages $\left(T_{\mathrm{L}}\right)$. Adults live for a maximum of approximately $10 \mathrm{~d}\left(T_{\mathrm{A}}\right)$, during which time they lay around 150 eggs $(\rho)$.

To estimate mortality rates, we use data presented by Scheepmaker et al. (1997) comprising two time series of fly abundance over a period of $6 \mathrm{wk}$ in a mushroom house in the absence of nematodes (see fig. $2 A, 2 B$ ). Their data show two distinct peaks of sciarid abundance, with a steady decline in abundance recorded after the peak of the second generation. As an approximation, we assumed that this decline in fly abundance represents the rate of adult mortality, thereby allowing us to estimate $\delta_{\mathrm{A}}$ directly from the data. To estimate adult mortality rate, we used a least squares method to fit the equation $N_{t}=\mathrm{N}_{0} \mathrm{e}^{-\delta_{\mathrm{A}} t}$, where $N_{t}$ is the number of flies present at time $t$ and $\mathrm{N}_{0}$ is the number at time 0 , to the region of sciarid decline (days 32-40) for the two time series presented by Scheepmaker et al. (1997) and solved for $\delta_{\mathrm{A}}$. From this, we obtained an estimate of adult mortality rate of $0.307 \pm 0.0615 \mathrm{~d}^{-1}$.

Sciarid larval mortality rate was estimated by using a least squares algorithm to vary $\delta_{\mathrm{L}}$ and obtain the best fit between the model and the time series presented by Scheepmaker et al. (1997). Through this process, we obtained estimates for larval mortality rate of 0.113 and 0.128 $\mathrm{d}^{-1}\left(\right.$ mean $\left.\pm \mathrm{SE}=0.121 \pm 0.0075 \mathrm{~d}^{-1}\right)$. Simulations of the parameterized model provide a reasonable fit to the data of Scheepmaker et al. (1997) in the absence of control (fig. 2A, 2B).

Nematode mortality rates in the field $(\mu)$ are system specific, depending on substrate type and abiotic factors (see Fenton et al. 2000 for a review). As for $\delta_{\mathrm{A}}$, we fitted the equation $N_{t}=N_{0} e^{-\mu t}$, where $N_{t}$ is the number of nematodes at time $t$, to time series data of Grewal and Richardson (1993), producing estimates for $\mu$ of $0.46,0.48$, 0.48 , and $0.47 \mathrm{~d}^{-1}\left(\right.$ mean $\left.\pm \mathrm{SE}=0.473 \pm 0.005 \mathrm{~d}^{-1}\right)$.

The major problem with validating host-pathogen models is the lack of information on the rate of transmission $(\beta)$. However, Scheepmaker et al. (1997) provide information on sciarid fly abundance on four sampling dates (days 3, 10, 24, and 38) following nematode application. Once again, we used a least squares algorithm to find the value of $\beta$ that provided the best fit to these data. Since we are dealing with pest and nematode densities throughout this article, $\beta$ has units of area per unit time (McCallum 2000).

The value of $\beta$ that provides the best fit between model and data is $2.2 \times 10^{-7} \mathrm{~m}^{2} \mathrm{~d}^{-1}$, although the model does deviate from the observed data (fig. 2C). In the model, we assume transmission rate is constant, whereas in reality it may vary with time, according to nematode and pest densities and other abiotic factors. It would be invaluable to carry out trials along the lines of those conducted by Dwyer and colleagues (Dwyer and Elkinton 1993; Dwyer et al. 1997) to estimate transmission rates independently 
Table 1: List and definition of model parameters

\begin{tabular}{ll}
\hline Symbol & \\
\hline$X$ & Susceptible pest density \\
$N$ & Free-living nematode density \\
$L, A$ & Pest's larval/adult density \\
$r$ & Intrinsic rate of increase of the pest population \\
$\beta$ & Per capita infection rate of nematodes \\
$\Lambda$ & Total number of nematodes produced per infected pest \\
$\mu$ & Mortality rate of nematodes (1/life expectancy) \\
$T_{\mathrm{I}}$ & Time between infection and lysis of cadavers \\
$T_{\mathrm{L}, \mathrm{A}}$ & Duration of pest's larval/adult stage \\
$\delta_{\mathrm{L}, \mathrm{A}}$ & Daily mortality rate of larval/adult pests \\
$\sigma_{\mathrm{L}, \mathrm{A}}$ & Probability of surviving larval/adult stage \\
$\rho$ & Number of viable eggs laid per adult pest \\
$X_{0}$ & Initial density of invading pests \\
$X_{\mathrm{T}}$ & Minimum viable pest density, below which extinction is assumed to occur \\
$N_{0}$ & Number of nematodes to apply to prevent pest invasion (preemptive application) \\
$L_{0}$ & Initial density of larval pests \\
$A_{0}$ & Initial density of adult pests \\
$d$ & Number of days between preemptive nematode application and pest attack \\
$\tau$ & Time in which to suppress an invading pest population through preemptive application \\
$\Gamma$ & Constant rate of nematode application \\
$\Gamma_{\mathrm{T}}$ & Threshold rate of constant nematode application needed to drive pest to extinction \\
\hline
\end{tabular}

and determine how they vary with nematode and pest density under field conditions.

Having shown that the stage-structured model provides a reasonable description of data sets dealing with the shortterm control of insect pests with entomopathogenic nematodes, we use this model framework to assess the optimum control method for four systems of agricultural importance where nematodes are currently used as control agents. The systems, which differ in crop and pest characteristics (as summarized in table 2), are sciarid flies in mushroom houses, black vine weevil, Otiorhynchus sulcatus (Coleoptera: Curculionidae) in strawberry fields, $O$. sulcatus in ornamental pot plants, and the Japanese beetle Popillia japonica (Coleoptera: Scarabaediae) in turfgrass plots. We now consider the relative benefits of the three control strategies described in the introduction of this article-inundative, preemptive, and constant (repeated) applications-in controlling these different pest systems.

\section{Can Nematodes Be Used Inundatively as Biological Pesticides?}

In this scenario, nematodes are applied in a single inundative release into an area of high pest density. In this case, the rate of initial pest suppression is the most important measure of success; subsequent behavior of the system is of less interest.

At present, no reliable analytical methods exist for estimating this initial rate of suppression. We therefore resort to a simulation approach to identify the key parameters determining the rate of control. All parameter values were based on those recorded in the literature (see Fenton et al. 2000 for a review), and we assumed an initial density of 10 adult pests per unit area invaded at time $t=0$. On day 20, a single dose of 10,000 nematodes per unit area was applied, which either died at a constant rate $\mu$ or infected pest larvae at rate $\beta$. Simulations were run for $100 \mathrm{~d}$ following application, and the time taken for the pest population to be suppressed to an arbitrarily low density (in this case, 0.1 per unit area), below which extinction was assumed to have occurred, was recorded. To help illustrate the results, we rescale the model's parameters relative to the time between infection and cadaver lysis $\left(T_{\mathrm{I}}\right)$; therefore, the rescaled larval duration $T_{\mathrm{L}}^{*}=$ $T_{\mathrm{L}} / \mathrm{T}_{\mathrm{I}}$, the rescaled adult duration $T_{\mathrm{A}}^{*}=T_{\mathrm{A}} / T_{\mathrm{I}}$, and $T_{\mathrm{I}}^{*}=$ 1. Hence, a single time step in the model now becomes equal to one nematode generation.

Increasing transmission efficiency $(\beta)$ had a large beneficial effect on the success of control; the time to suppress the pest population shows a dramatic decline with increasing $\beta$ (fig. 3A). However, as infection efficiency increased further, the return, in terms of the reduction in the time taken to suppress the pest population, declined. Hence, there is less to be gained by spending time and energy improving nematode infection rates beyond a certain level. The level of nematode mortality in the field $(\mu)$ has a less drastic effect, although, as $\mu$ decreases, there is a corresponding decrease in the time taken to suppression 


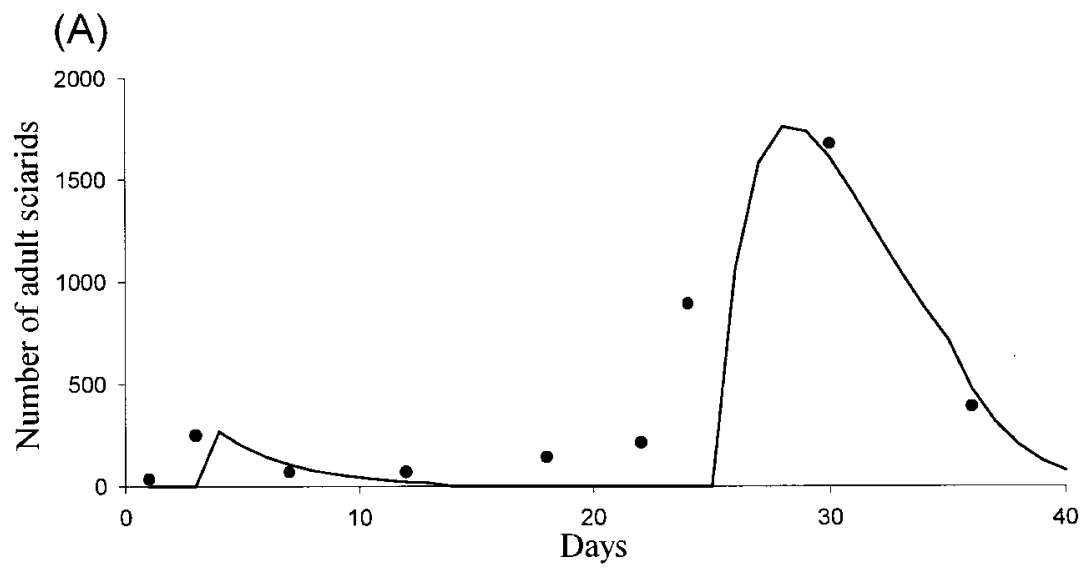

(B)

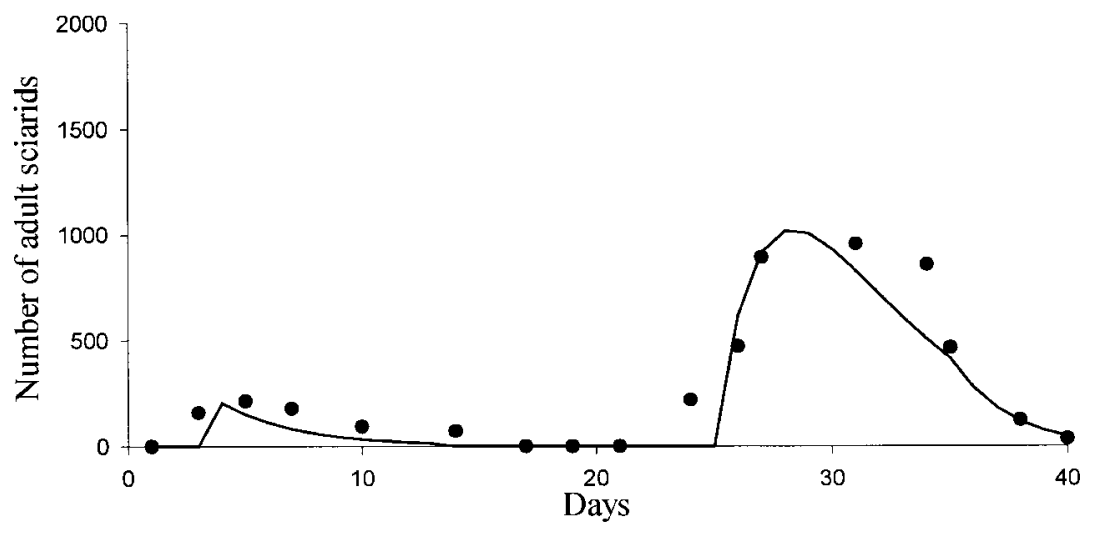

(C)

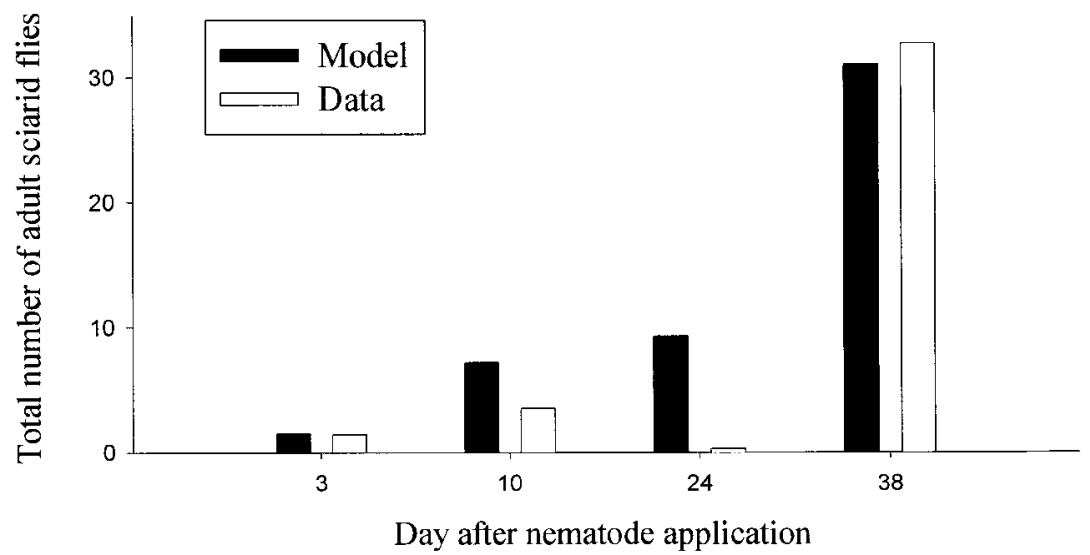

Figure 2: Predictions of the stage-structured model (lines) and data from Scheepmaker et al. (1997; points) showing the number of sciarid flies present in a mushroom house in the absence of nematodes for two replicates $(A) \delta_{\mathrm{L}}=0.113 \mathrm{~d}^{-1}$ and $(B) \delta_{\mathrm{L}}=0.128 \mathrm{~d}^{-1}$. Also shown is the bestfit model prediction $(C)$ to the data of Scheepmaker et al. (1997) following a total dose of $6 \times 10^{6}$ nematodes $\mathrm{m}^{-2}$ applied at day 0 . Best-fit parameter values are $T_{\mathrm{I}}=14 \mathrm{~d} ; T_{\mathrm{L}}=20 \mathrm{~d} ; T_{\mathrm{A}}=10 \mathrm{~d} ; \delta_{\mathrm{A}}=0.3 \mathrm{~d}^{-1} ; \rho=150 ; \Lambda=10,000 ; \mu=0.47 \mathrm{~d}^{-1} ;$ and $\beta=2.2 \times 10^{-7} \mathrm{~m}^{2} \mathrm{~d}^{-1}$. 
Table 2: Main characteristics of the four crop-pest systems studied

\begin{tabular}{lllccc}
\hline & \multicolumn{1}{c}{ Pest species } & $\begin{array}{c}\text { Host } \\
\text { reproductive } \\
\text { rate } \\
\text { Crop }\end{array}$ & $\begin{array}{c}\text { Nematode } \\
\text { mortality } \\
\text { rate } \\
(\mu)\end{array}$ & $\begin{array}{c}\text { Transmission } \\
\text { rate } \\
(\beta)\end{array}$ & $\begin{array}{c}\text { Crop } \\
\text { sustainable } \\
\text { injury level }\end{array}$ \\
\hline Mushrooms & Sciarid fly Lycoriella spp. & High & Low & High & Low \\
Strawberries & Black vine weevil Otiorhynchus sulcatus & Low & High/middle & High & Middle \\
Ornamentals & Black vine weevil O. sulcatus & Low & Low & High & Low \\
Turf & Japanese beetle Popillia japonica & Middle/low & High & Low & High \\
\hline
\end{tabular}

Note: It is assumed that crops grown in protected environments, such as glasshouses or grow bags, are likely to have relatively low nematode mortality rates. Similarly, it is assumed that in enclosed, protected environments transmission is likely to occur faster than in exposed field crops. The sustainable injury level of a crop is an indication of how much damage the crop can endure while remaining commercially viable.

(fig. 3A). This is especially true at low levels of transmission.

The effect of the duration of the pest's larval stage $\left(T_{\mathrm{L}}^{*}\right)$ on the time taken to suppress the pest population is more complex (fig. $3 B$ ). At all values of nematode production $(\Lambda)$, there is a humped relationship between the duration of the larval stage and the time to pest extinction. Pests with short-duration larval stages (less than three or four nematode generations) become extinct within only a few bouts of nematode recycling (fig. $3 B$ ). These pests, by passing through a number of generations in quick succession, provide regular recruitment of large numbers of new susceptible larvae. These larvae quickly become infected, producing massive numbers of new nematodes that remain at high densities during the periods of larval absence so that, within a few bouts of nematode recycling, short-lived pests are quickly driven to extinction.

However, for larval stages of intermediate duration (approximately four or five nematode generations), each successive bout of infection (within a single pest generation) occurs with fewer and fewer susceptible larvae. Hence, the rate of nematode production (effectively, $\Lambda \beta L N$ ) becomes lower and lower as available hosts $(L)$ become rarer and rarer. Providing $T_{\mathrm{L}}$ is short enough to ensure this process does not carry on long enough to drive the pest to extinction, the remaining larvae mature to nonsusceptible adults, meaning there are too few nematodes present to infect the next generation of susceptible larvae. Hence, the pest population escapes extinction. However, for pests with long-lived larval stages (greater than around six nematode generations), the period of initial larval presence is sufficient to ensure that, although each successive bout of infection produces fewer and fewer nematodes, the susceptible larvae are present long enough for all to be infected before they can mature to adults and replenish the population.

Clearly, increasing $\Lambda$ leads to a reduction in the time to suppress the pest population, as more nematodes are present to infect (fig. $3 B$ ). In addition, the fewer nematodes that are produced per cadaver means it is easier for shorter- lived pests (those with lower values of $T_{\mathrm{L}}$ ) to escape extinction (fig. $3 B$ ), as each successive bout of infection produces correspondingly fewer new nematodes.

This analysis indicates that inundative application of nematodes following pest invasion is ideally suited to a pest with either a long-lived larval stage (greater than approximately six nematode generations) or a very short one (less than approximately four nematode generations). It is also important to have low nematode mortality rates and high transmission rates (table 3 ). In addition (although possibly not as important), it may be preferable for the crop to be able to sustain at least some damage before the nematodes are applied (i.e., sustainable injury level is moderately high). Inundative control, therefore, may be best used for the sciarid fly-mushroom system, providing it occurs early enough to prevent damage to the crop and conditions maintain low nematode mortality rates. However, it would be inappropriate for black vine weevils on strawberries, where nematode mortality is relatively high.

\section{Can Nematodes Be Used as Preemptive Control Agents?}

This control strategy involves the early application of nematodes to prevent the escalation of an expected pest attack (nematode-in-first technique; Kaya 1993). Such an approach has been used to inoculate soil where seedlings have been planted, to create a nematode barrier so insects are infected as they enter the soil (Pye and Pye 1985; Smith et al. 1993). This application could occur either before a predicted pest invasion or during the time window (determined by the duration of the pest's egg stage) between the first observation of adults and the emergence of the harmful larval stages.

Due to problems of intractability of the stage-structured model, we adopted an analytical approach based on a simplified model and then verified the findings using simulations of the stage-structured model. For the purposes of this model, we assumed that a single dose of $N_{0}$ nematodes per unit area was applied $d$ days before pest attack, which 
(A)

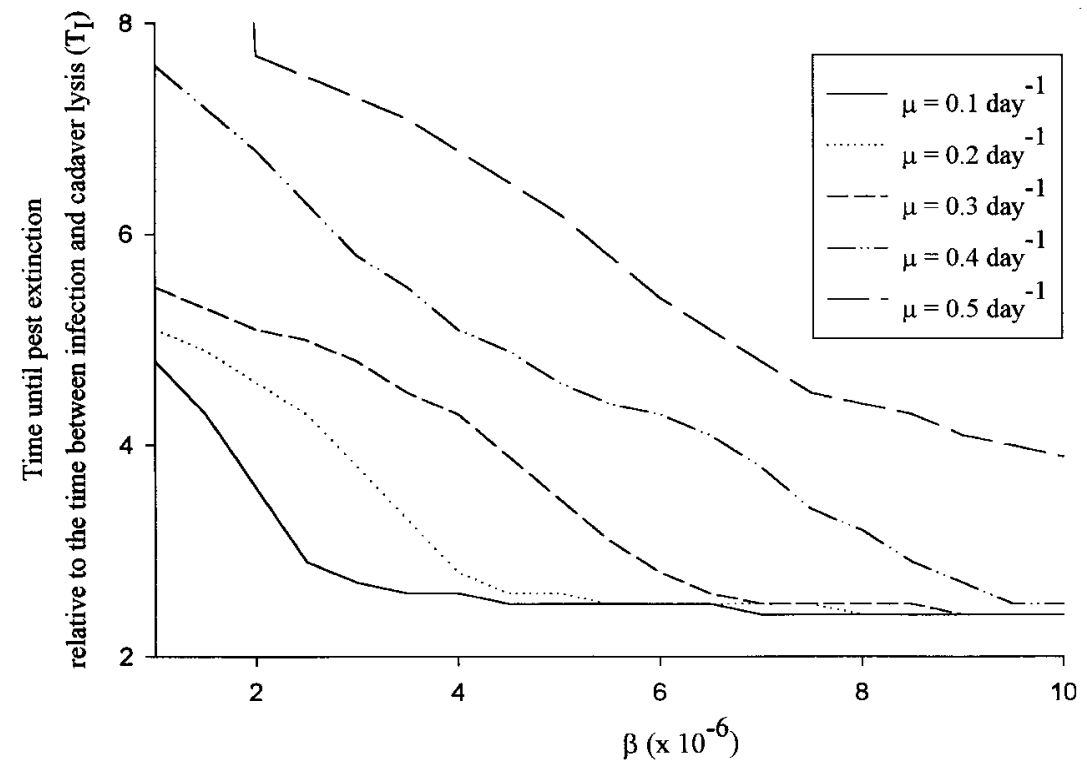

(B)

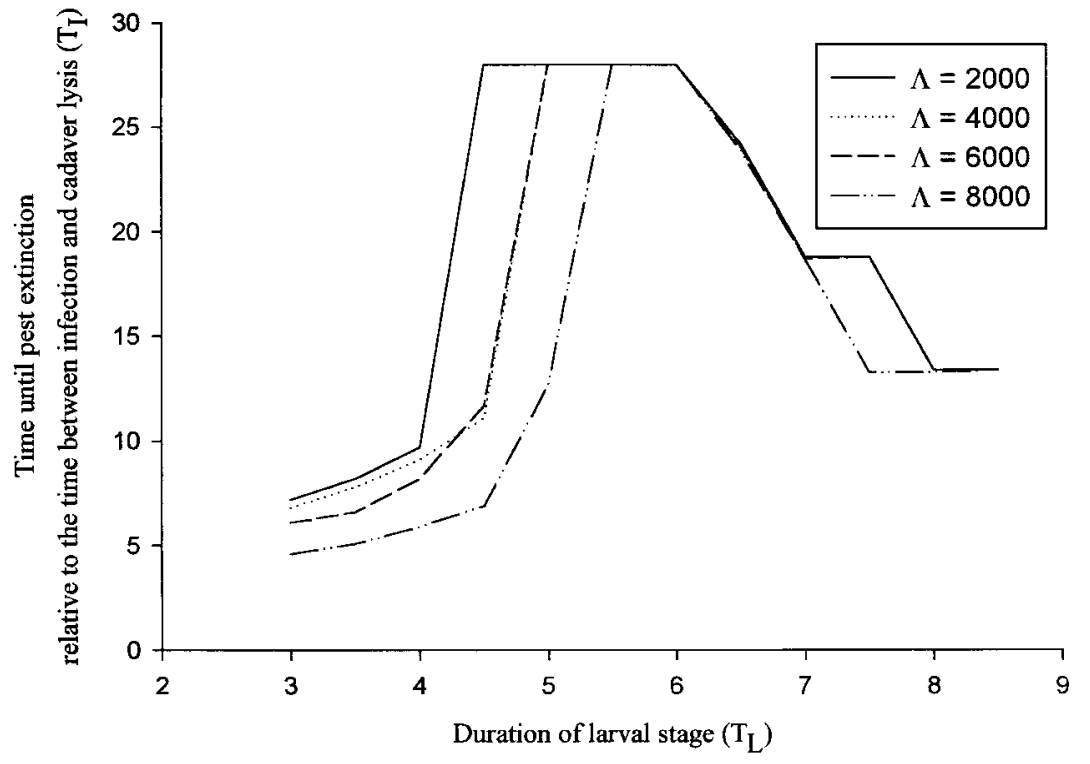

relative to the time between infection and cadaver lysis $\left(\mathrm{T}_{\mathrm{I}}\right)$

Figure 3: $A$, Effect of transmission rates $(\beta)$ and nematode mortality rates $(\mu) . B$, Number of nematodes produced per cadaver $(\Lambda)$ and duration of the pest's larval stage $\left(T_{\mathrm{L}}\right)$ on the relative time taken to suppress a pest population. Unless otherwise stated, initial density of adult pests invading $=10$ per unit area; $T_{\mathrm{I}}=14 \mathrm{~d} ; T_{\mathrm{L}}=20 \mathrm{~d} ; T_{\mathrm{A}}=10 \mathrm{~d} ; \delta_{\mathrm{L}}=0.1 \mathrm{~d}^{-1} ; \delta_{\mathrm{A}}=0.3 \mathrm{~d}^{-1} ; \rho=150 ; \Lambda=10,000 ; \mu=0.1 \mathrm{~d}^{-1} ;$ and $\beta=$ $0.0000005 \mathrm{~m}^{2} \mathrm{~d}^{-1}$. 
Table 3: Summary of the ideal parameter values for each short-term control strategy examined

\begin{tabular}{llllccc}
\hline $\begin{array}{l}\text { Application } \\
\text { method }\end{array}$ & \multicolumn{1}{c}{$r$} & \multicolumn{1}{c}{$\begin{array}{c}\text { Sustainable } \\
\text { injury level }\end{array}$} & Best system & Worst system \\
\hline Inundative & $\begin{array}{c}\text { Very high } \\
\text { or very low }\end{array}$ & Low & Very high & High & Sciarid fly/mushrooms & $\begin{array}{c}\text { Black vine weevil/ } \\
\text { strawberries }\end{array}$ \\
Preemptive & Low & Very low & High & Low & $\begin{array}{c}\text { Black vine weevil/ } \\
\text { ornamentals }\end{array}$ & $\begin{array}{c}\text { Popillia japonical } \\
\text { turfgrass }\end{array}$ \\
Repeated & Low & Low & High/middle & High & P. japonica/turfgrass & Sciarid fly/mushrooms \\
\hline
\end{tabular}

Note: Included are systems where control is most likely and least likely to be achieved.

died at a constant rate, $\mu$. Nematode recycling typically does not occur until at least $2 \mathrm{wk}$ following infection, and since it is desirable for pest suppression to occur before this time, we assume there to be no recycling of nematodes $(\Lambda=0)$. Hence, at time $t$, following pest invasion, there are $N_{0} \mathrm{e}^{-\mu(\mathrm{t}+\mathrm{d})}$ nematodes in the environment. The pest population invades at time $t=0$, when there will be no density-dependent processes acting on the pest, so they reproduce at a constant per capita rate, $r$. Surviving nematodes infect pests at a constant, density-independent rate, $\beta$. Details of the model and analysis are given in appendix B. From this simple model, we know, first, that suppression of the pest will occur provided

$$
N_{0} \geq \frac{r \mathrm{e}^{\mu d}}{\beta}
$$

Second, we can derive the following expression for the density of nematodes that need to be applied to suppress the pest from an initial density of $X_{0}$ to a predefined threshold density $\left(X_{\mathrm{T}}\right)$, within time $\tau$ following pest invasion (see app. B):

$$
N_{0}=\frac{\mu \mathrm{e}^{\mu d}\left[r \tau-\ln \left(X_{\mathrm{T}} / X_{0}\right)\right]}{\beta\left(1-\mathrm{e}^{-\mu \tau}\right)}
$$

The term $X_{\mathrm{T}} / X_{0}$ is a measure of the degree of required suppression and is influenced by the density of invading pests; clearly, the greater the initial pest challenge, the more difficult they are to suppress. Likewise, if the desired level of pest suppression is particularly low, more nematodes need to be applied. Similarly, if the desired time limit in which suppression is required $(\tau)$ is small, more nematodes are needed.

By varying $d$, estimates can be made of the maximum and minimum numbers of nematodes needed for preemptive control, depending on the time of pest invasion. As the time between nematode application and pest attack increases (large $d$ ), so a larger dosage needs to be applied to overcome nematodes lost through mortality. If this delay is large, the effect of nematode mortality $(\mu)$ becomes increasingly important (as seen in the exponent in the numerator of eq. [1]). In addition, the dosage of nematodes decreases as transmission efficiency $(\beta)$ increases, and as the pest's reproductive rate $(r)$ increases, so the required dosage of nematodes increases.

To explore the validity of these predictions from the simplified model, we ran simulations of the stage-structured model. For this analysis, we assumed a challenge of 100 adult pests per unit area and determined the number of nematodes needing to be applied to reduce the pest to an arbitrarily low density ( 0.1 per unit area) within $10 \mathrm{~d}$.

As suggested by equation (1), the rate of infection $(\beta)$ can greatly affect the density of nematodes to apply (fig. $4 A$ ). Under all conditions, low rates of infection (small $\beta$ ) require a high density of nematodes to be applied. As infection efficiency is increased, there is initially a large decrease in the required dosage of nematodes. However, once again, the rate of gain in control success declines as $\beta$ is increased. Nematode mortality rates are also very important; the number of nematodes needed to suppress the pest greatly reduces at low values of $\mu$. Clearly, as nematode mortality rates increase, more need to be applied to prevent successful invasion of the pest.

Finally, equation (1) suggests that fewer nematodes should be needed for preemptive application if the pest has a low growth rate $(r)$. To determine the validity of this finding, we need to express $r$ in terms of the parameters of the stage-structured model. In the absence of nematodes, the pest population increases at a rate determined by the number of eggs laid and the probabilities of surviving the larval and adult stages. Hence, the per capita daily rate of increase of the pest is

$$
\frac{\rho \mathrm{e}^{-\delta_{\mathrm{L}} T_{\mathrm{L}}} \mathrm{e}^{-\delta_{\mathrm{A}} T_{\mathrm{A}}}}{T_{\mathrm{L}}+T_{\mathrm{A}}} .
$$

Clearly, as the number of eggs laid per female $(\rho)$ increases, so does the growth rate $(r)$. In addition, as the duration of either the larval or the adult stage increases, the growth rate decreases. Therefore, all other things being equal, species with long-lived larval or adult stages (univoltine pests) have lower growth rates and should be, according to equation (1), easier to control with a preemptive application. 


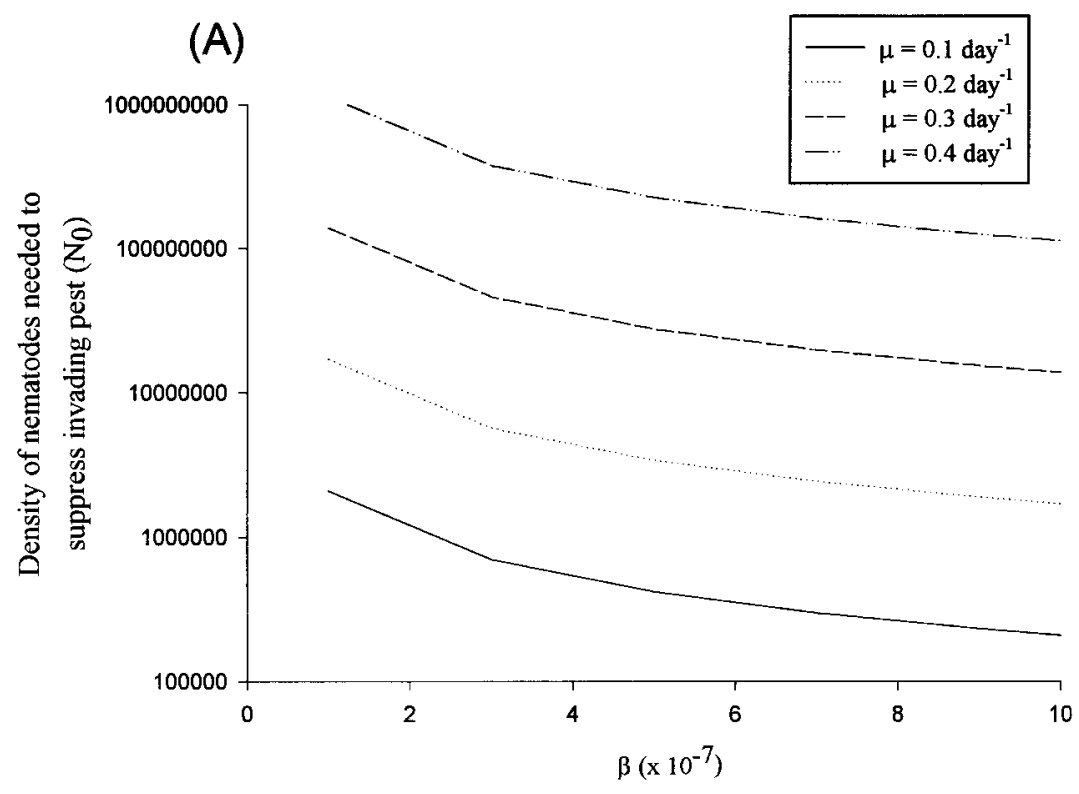

(B)

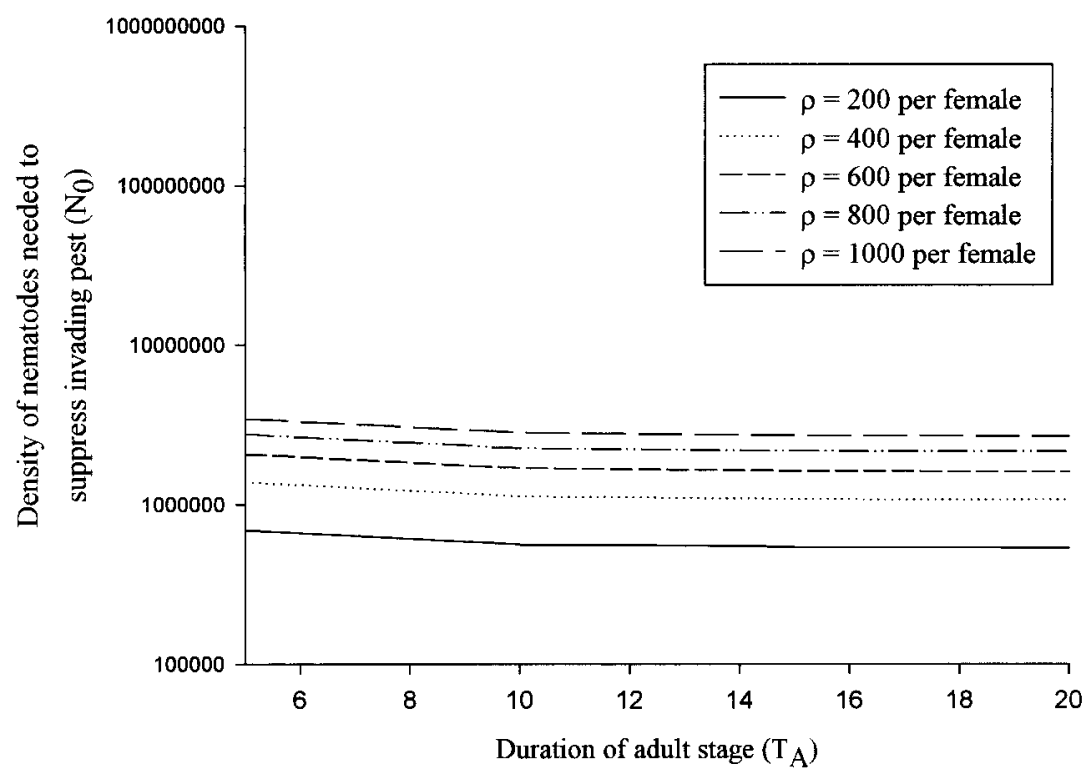

Figure 4: Density of nematodes needing to be applied in a preemptive manner to suppress an invading pest population from an initial level of 100 per unit area to below a minimum viable level of 0.1 within $10 \mathrm{~d}$. A, Effect of transmission rate $(\beta)$ and nematode mortality rate $(\mu)$ for nematodes applied on the same day as pest attack $(d=0) . B$, Effect of the duration (in days) of the adult stage $\left(T_{\mathrm{A}}\right)$ and the number of eggs laid per female $(\rho)$. Unless otherwise stated, $T_{\mathrm{I}}=14 \mathrm{~d} ; T_{\mathrm{L}}=20 \mathrm{~d} ; T_{\mathrm{A}}=10 \mathrm{~d} ; \delta_{L}=0.1 \mathrm{~d}^{-1} ; \delta_{\mathrm{A}}=0.3 \mathrm{~d}^{-1} ; \rho=150 ; \Lambda=10,000 ; \beta=0.0000005 \mathrm{~m}^{2} \mathrm{~d}^{-1} ;$ and $\mu=0.1 \mathrm{~d}^{-1}$.

Simulations of the stage-structured model agree, at least in part, with the predictions from equation (1); as the number of eggs laid per female $(\rho)$ increases, so does the dose of nematodes required to suppress the pest popu- lation (fig. 4B). However, the duration of the adult stage $\left(T_{\mathrm{A}}\right)$ has very little effect on the required dose. Similar findings are seen for varying the duration of the larval stage, $T_{\mathrm{L}}$ (not shown). Clearly, at the time scales under 
consideration here, where suppression is required within $10 \mathrm{~d}$, the longevity of the respective stages has no impact on control success.

To summarize, preemptive control may be most suitable for systems where transmission rates are high and nematode mortality rates are low. Hence, it is more appropriate for sheltered crop environments, such as glasshouses, where exposure to harsh climatic conditions and predation is minimal (table 3 ). In addition, if a crop has a very low sustainable injury level, it may be preferable to use preemptive control in an attempt to prevent any damage occurring to the crop. To this end, preemptive control may be ideally suited to the black vine weevil-ornamental pot plant system and least applicable to the Japanese beetle-turfgrass system.

To determine the relative benefits of preemptive application compared to applying nematodes after pest invasion, simulations were run for $100 \mathrm{~d}$ following pest attack, and both the dosage of nematodes applied and the timing of this single application were varied relative to the time of pest invasion. The effect of nematode mortality rates was also considered. Assuming that overall crop damage is related to the total number of pests present throughout the year, then the appropriate measure of control success is the cumulative density of pests observed throughout this period.

The timing of application can have major effects on control success (fig. 5). In general, treatment should take place as close as possible to the day of pest invasion, regardless of the number of nematodes applied or their subsequent mortality rates. If application occurs too late, the pests escape the regulatory role of the nematodes, particularly if nematode mortality rates are high (fig. $5 A, 5 B$ ). However, if the time of pest invasion can be predicted with reasonable accuracy, it may prove effective to apply nematodes preemptively, rather than after pest invasion. This would be especially true if the crop had zero tolerance to damage and needed complete protection (e.g., ornamentals). Clearly, this is most applicable if levels of nematode mortality are low to prevent large numbers dying before the pests arrive (cf. fig. $5 A$ with $5 B$ ).

\section{Can a Constant Rate of Nematode Application Suppress a Pest Population?}

Until now, we have concentrated specifically on the effects of single, inundative applications on the short-term suppression of the pest population. Biological control agents can also be used in an augmentative (inoculative) manner, where several releases of a (low) dose are applied throughout the control period. This differs from classical biological control, where only a single release of control agents is needed to bring about long-term suppression of the pest.
To determine what rate of nematode application is needed to achieve constant pest suppression, we assume that nematodes are applied at a constant rate, $\Gamma$, throughout the desired control period. Anderson and May (1981) carried out such an analysis using a simple host-pathogen model, finding a threshold nematode application rate $\left(\Gamma_{\mathrm{T}}\right)$ above which host extinction always occurred:

$$
\Gamma_{\mathrm{T}} \geq \frac{r \mu}{\beta}
$$

For our system, we carry out a similar analysis but using the stage-structured model as our starting point (see app. $C$ for full details). There are two stable states: the coexistence equilibrium $\left(L^{*}, A^{*}, N^{*}\right)$ as defined in appendix C and, as Anderson and May (1981) found, a new stable state $(0,0, \Gamma / \mu)$, corresponding to the nematodes being applied at a sufficiently high rate to drive the pest population to extinction. The nematodes are maintained by a balance between introduction $(\Gamma)$ and death $(\mu$; Anderson and May 1981). The alternative equilibrium $\left(L^{*}, A^{*}, N^{*}\right)$ represents the state of the system if application rates are not high enough to drive the pest population to extinction. Inspection of the equations for $L^{*}, A^{*}$, and $N^{*}$ (app. C) reveal that, for this state to be relevant (i.e., $L^{*}, A^{*}$, $N^{*}>0$ ), the following condition has to be fulfilled:

$$
\rho \mathrm{e}^{-\left[\left(\Gamma \beta T_{\mathrm{L}} / \mu\right)+\delta_{\mathrm{L}} T_{\mathrm{L}}\right]}>1,
$$

which is the basic reproductive ratio $\left(R_{0}\right)$ of the nematode. So, to be viable, the number of eggs laid that survive all mortality factors (infection and natural mortality) to reach adulthood must be $>1$. If this condition is not fulfilled, then the system will shift to the state $(0,0, \Gamma / \mu)$, where extinction of the pest has occurred. By rearranging equation (3), we obtain the following expression for a threshold rate of nematode application $\left(\Gamma_{\mathrm{T}}\right)$, above which pests cannot survive (app. C):

$$
\Gamma_{\mathrm{T}}=\frac{\mu}{\beta T_{\mathrm{L}}}\left[\ln (\rho)-\delta_{\mathrm{L}} T_{\mathrm{L}}\right]
$$

Note that we make no comment about the stability of the equilibria; all we claim is that if equation (4) is fulfilled, then the pest population, ultimately, will be driven to extinction. Hence, $\Gamma_{\mathrm{T}}$ can be thought of as the minimum application rate guaranteed to bring about pest suppression. It is quite possible that the pest may become extinct at doses lower than $\Gamma_{\mathrm{T}}$ if, for instance, sufficient degrees of cyclic behavior are induced.

Clearly, the rate of nematode production has no effect on the suppression of the pest population under these conditions ( $\Lambda$ and $T_{\mathrm{I}}$ do not appear in eq. [4]). Once again, 
(A)

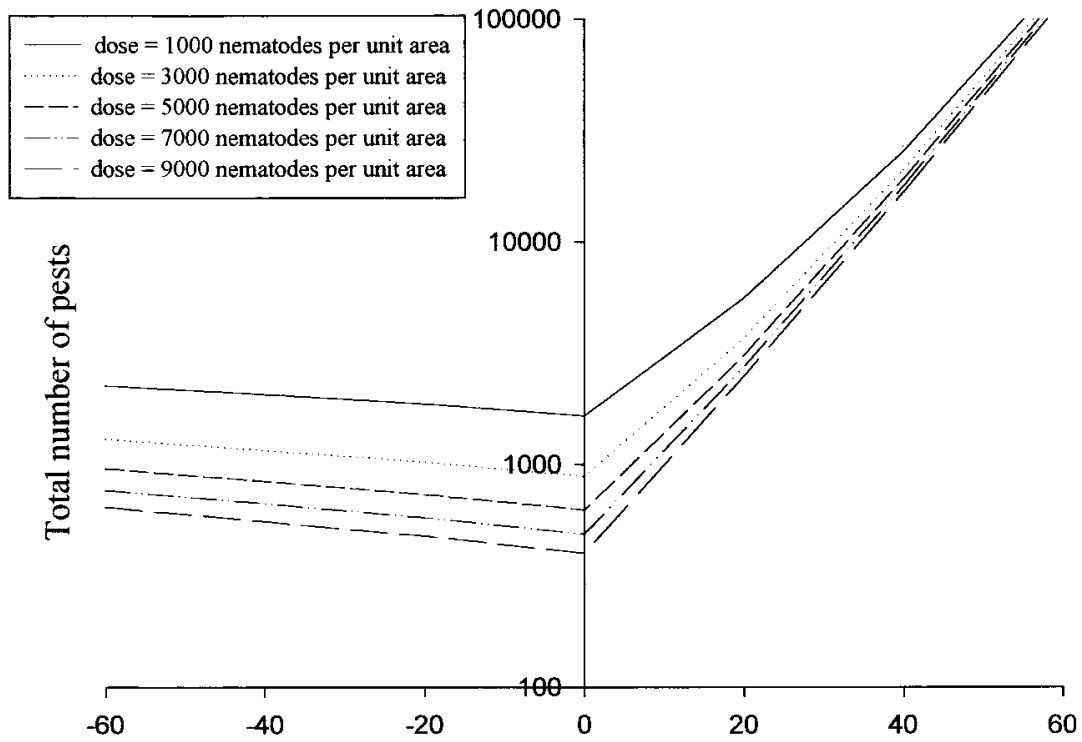

(B)

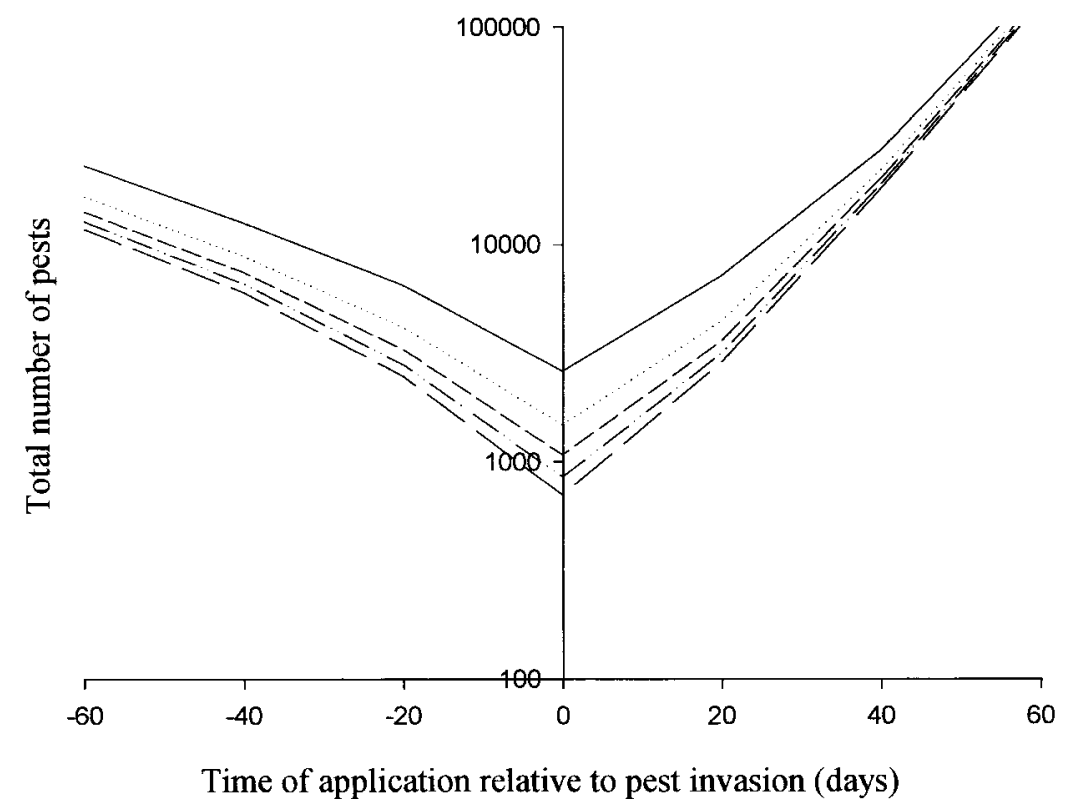

Figure 5: Effect of the density of nematodes applied and timing (relative to the time of pest attack) of a single, inundative application of nematodes on the cumulative density of pests observed throughout a year, as estimated from numerical simulations of the stage structured model. $A, \mu=$ $0.01 \mathrm{~d}^{-1} ; B, \mu=0.1 \mathrm{~d}^{-1}$. Density of invading adult pests $=10$ per unit area; $T_{\mathrm{I}}=14 \mathrm{~d} ; T_{\mathrm{L}}=20 \mathrm{~d} ; T_{\mathrm{A}}=10 \mathrm{~d} ; \delta_{\mathrm{L}}=0.1 \mathrm{~d}^{-1} ; \delta_{\mathrm{A}}=0.3 \mathrm{~d}^{-1} ; \rho=$ $150 ; \Lambda=10,000 ;$ and $\beta=0.0000005 \mathrm{~m}^{2} \mathrm{~d}^{-1}$.

control is enhanced if infection is rapid (high $\beta$ ) and nematode mortality rates are low (small $\mu$ ). Furthermore, suppression is easier if the pest has a long-lived larval stage (large $T_{\mathrm{L}}$ ) to ensure a prolonged period during which nematode infection can occur.
This analytical model assumes a constant trickle of nematodes applied continuously throughout the control period. However, in reality, it is more likely that nematodes would be applied at certain intervals. To explore this effect, we carried out numerical simulations of the new model, 
incorporating nematode applications of a fixed dosage at regular, discrete intervals. It should be noted that, although the period between applications was varied, the same overall application rate was maintained (in terms of nematodes per day, averaged over the whole control period). For example, an average application rate of 40,000 nematodes per unit area per day could be applied as batches of 200,000 every $5 \mathrm{~d}$ or 400,000 every $10 \mathrm{~d}$, and so forth. Simulations were run for up to $1,000 \mathrm{~d}$ following pest invasion (100 adult pests per unit area invaded at $t=0$ ), and the time taken for the pest population to reach an arbitrarily low density below which extinction was assumed to have occurred ( 0.1 per unit area) was recorded. It should be noted that, although simulations were run for up to $1,000 \mathrm{~d}$ for illustrative purposes, it is only those combinations of nematode dosage and timing that lead to pest extinction within considerably shorter periods of time (depending on the desires of the specific control program) that can truly be deemed to be successful.

The predictions of these simulations are in general agreement with the analytical results (fig. 6); application rates above $\Gamma_{\mathrm{T}}$ (for the parameter values used, $\Gamma_{\mathrm{T}}=$ 30,100 per unit area per day) always resulted in extinction of the pest population. At no point did an application rate of $30,000 \mathrm{~d}^{-1}$ drive the pest population to extinction within $1,000 \mathrm{~d}$. As the dosage was further increased above this threshold, the time taken to drive the pest population to extinction, not surprisingly, declined.

However, what is not apparent from the analytical solution is that the period between applications can have important consequences for the short-term success of control, even though the end result (pest suppression or not) is the same. As the time between applications increased, there was a gradual increase in the time taken to suppress the pest, as this allowed the pest population to build up to large numbers before the next dose was applied (fig. 6).

In addition, it is noticeable that, regardless of the dosage of nematodes applied, the efficiency of control appears to cycle with a period of $25 \mathrm{~d}$; applications were least effective if applied either 25 or $50 \mathrm{~d}$ apart (fig. 6). No such pattern emerges if the same procedure is carried out with a nonstage-structured model. This is due to the discrete nature of the stage-structured life cycle in conjunction with the invulnerable adult stage, meaning that nematodes applied when the majority of pests are in the adult stage are wasted.

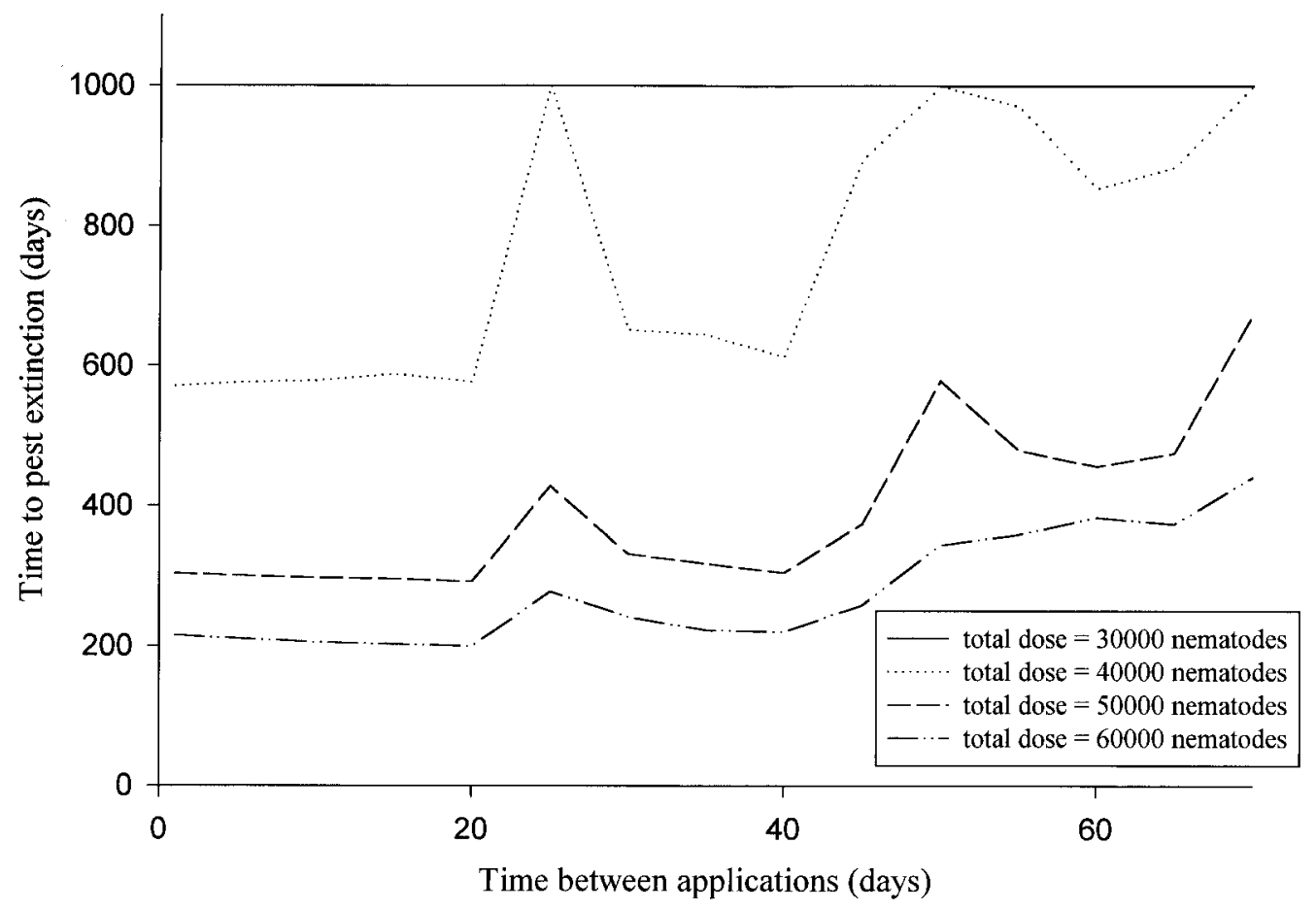

Figure 6: Effect of constant nematode application rates on the time to drive a pest population to extinction, as estimated from numerical simulations of the stage-structured model. The overall frequency of application was maintained the same across a run (300,000; 400,000; 500,000; or 600,000 nematodes per unit area per day), but nematodes were applied at different intervals. Initial density of adult pests invading $=100$ per unit area; $T_{\mathrm{I}}=14 \mathrm{~d} ; T_{\mathrm{L}}=20 \mathrm{~d} ; T_{\mathrm{A}}=10 \mathrm{~d}, \delta_{\mathrm{L}}=0.1 \mathrm{~d}^{-1} ; \delta_{\mathrm{A}}=0.3 \mathrm{~d}^{-1} ; \rho=150 ; \Lambda=10,000 ; \mu=0.1 \mathrm{~d}^{-1} ;$ and $\beta=0.0000005 \mathrm{~m}^{2} \mathrm{~d}^{-1}$. At these parameter values, the predicted threshold application rate to suppress the pest population is $30,100 \mathrm{~d}^{-1}$. 
The simulations in figure 6 assumed an adult period of $10 \mathrm{~d}$ and a larval period of $20 \mathrm{~d}$. Since the initial cohort of invading pests were adults, applications every $25 \mathrm{~d}$ from then coincided with the next generation of invulnerable adults, thereby losing the effect of control. Therefore, such applications should be closely tied in with the pest life cycle, applying to coincide with the presence of the most susceptible stages, to ensure maximum efficiency and speed of kill.

To summarize, constant (repeated) applications are most appropriate for systems where pest larval stages are long lasting (to prevent substantial pest buildup between treatments and allow prolonged periods of nematode infection) or where the crop has a high sustainable injury level (enabling treatments to be infrequent with little damage to the crop). Alternatively, the application method should be inexpensive, thereby allowing many treatments. Therefore, it may be best to use repeated applications to control the Japanese beetle-turfgrass system where the crop can sustain high levels of damage and the pest has a relatively low reproductive rate (table 3 ). Ornamental plants and mushroom crops, however, typically have little tolerance for damage, and unless application costs are low, this control method is unlikely to be appropriate.

\section{Discussion}

This article explored the importance of transient dynamics of a parasite-host system in relation to the application of a biological control agent. More specifically, we used general modeling techniques to explore the potential for entomopathogenic nematodes to be used as short-term biological control agents of invertebrate crop pests. Such an approach differs from that used in many analytical models of biological control where it is the equilibrium (longterm) dynamics that are the measure of control success (e.g., Hassell and May 1974; Anderson and May 1981; Begon et al. 1992; Briggs et al. 1995). In reality, though, control success does not depend simply on the long-term abundance of the pest population. It may not matter how strongly the pest population is reduced or for how long suppression persists if it takes years to achieve that suppression.

Depending on the objectives of the control program, it may be more desirable to achieve rapid, short-term control, in which case the initial rate of pest suppression will greatly influence the choice of control agent. This is particularly important in agriculture where crop lifetimes are typically short (1-5 mo). Furthermore, short-term biological control may be desirable since it can reduce the long-lasting detrimental impact of the control agent on nontarget hosts. Therefore, we set out to evaluate the immediate, transient behavior of the pest-nematode system under three different application strategies: inundative application, preemptive application, and constant, augmentative application. This analysis allows us to examine how different life-history strategies affect control success and so enable us to determine which method of control is most suitable to combat different pest species.

The most important parameter in determining control success is the rate of transmission, $\beta$. For preemptive and inundative control, if transmission rates are low (as may be the case), control will be greatly enhanced by a slight improvement in transmission (see figs. $3 A, 4 A$ ). Such an improvement could be achieved by strategic application so that nematodes are applied in close proximity to high aggregations of pests (e.g., around host-plant root systems) or by altering soil conditions to maximize nematode survival and dispersal. However, if transmission rates are high, there is little benefit of further improvements in transmission, irrespective of the method of control.

Simulations showed that, to prevent any damage occurring, it may be preferable to apply nematodes before pest invasion (fig. 5), possibly during the time window between adult arrival and larval emergence. However, the success of this approach relies on low levels of nematode mortality. A number of field trials have shown that survival can be enhanced if plots are heavily irrigated both before and after application, thereby increasing the period for which preemptive control is viable (Georgis and Gaugler 1991; Downing 1994). The results of a series of trials carried out by Feaster and Steinkraus (1996) on the use of Steinernema riobravis as a control agent of the corn earworm Helicoverpa zea agree with our findings; nematodes applied $24 \mathrm{~h}$ before pest invasion resulted in greater suppression than a larger dose of nematodes applied $24 \mathrm{~h}$ after pest invasion. Additionally, irrigated plots produced greater rates of suppression than nonirrigated, through enhanced nematode survival. Such preemptive treatments are rare (although see Pye and Pye 1985; Smith et al. 1993) but, based on these predictions, are an area where further research could be directed, particularly for glasshouse crops where nematode mortality may be low.

The third method of application we explored involved applying nematodes at regular intervals throughout the control period. Our results showed that the frequency of application could have a significant effect on the shortterm success of control; leaving a large period between applications allows the pest to build up before suppression occurs (fig. 6). Once again, applications have to be strategically timed to coincide with the presence of large numbers of the most susceptible stage of the pest's life cycle. Assuming that a financial cost is incurred at each time of application, the farmer faces a trade-off between the frequency of application and the density of pests occurring before effective control. Clearly, the economic injury level 
of the crop needs to be considered before deciding on the optimum timing of application. If the crop can sustain high levels of damage, it may prove more efficient to apply a few large doses rather than many small ones.

Many of these details concerning the optimal use of entomopathogenic nematodes as short-term biological control agents would be overlooked using traditional, equilibrium analyses of host-parasite models. However, by examining the transient dynamics of the system, it is possible to determine successful methods of application even if the control agent cannot persist sufficiently to be used for classical biological control. Such an approach is rarely used in biological control theory, although Gilligan and colleagues examined the transient dynamics of a variety of host-pathogen models to explore the dynamics of various plant pathogen systems (Kleczkowski et al. 1996; Gubbins and Gilligan 1997; Truscott et al. 1997; Bailey and Gilligan 1999; Truscott et al. 2000). They showed, as here, that the initial density of inoculum can have a profound effect on the shape of the disease epidemic curves and also on the variability of the system as a whole (Kleczkowski et al. 1996; Bailey and Gilligan 1999). Through these shortterm analyses, it is possible to accurately assess dynamic behavior, even when the system is periodically disturbed, for instance, by abiotic seasonal fluctuations or cropping cycles. Such an approach is invaluable for determining practical application strategies of biological control agents in the field.

As mentioned previously, the life history of entomopathogenic nematodes means that many of the results presented here can be generalized to other biological control agents; most of the key findings are more due to the biology of the pest rather than specifically to entomopathogenic nematodes. In the majority of cases, it is the stage structure of the pest coupled with larval susceptibility (features that apply for other biological control agents such as viruses or parasitoids) that leads to the importance of the timing of application. As such, we recommend the approach adopted here when considering the practical use of models in determining optimum methods of application of biological control agents.

However, despite having much in common with other parasites, entomopathogenic nematodes do not fit neatly into any single group (Hudson and Norman 1995). This becomes important when considering specific control scenarios. For instance, the presence of an active host-seeking stage means that transmission rates may be higher than those of microparasites, where $\beta$ has been estimated to be nearer to $2 \times 10^{-12} \mathrm{~d}^{-1}$ (Dwyer and Elkinton 1993; Goulson et al. 1995; D'Amico et al. 1996) than to $2 \times 10^{-7} \mathrm{~d}^{-1}$, as was estimated for entomopathogenic nematodes here.

At present, the model does not take into account any spatial structuring. As with other host-parasite systems, incorporating spatial effects can lead to radically different conclusions about the prevalence of infection and stability of the system (Comins et al. 1992; Wood and Thomas 1996; Rohani and Ruxton 1999). However, although a number of surveys have shown that entomopathogenic nematodes are distributed in a highly aggregated manner in the wild (Hominick and Briscoe 1990; Boag et al. 1992; Campbell et al. 1998), we do not believe this to be an important oversight in this work. For control, nematodes are applied in densities far greater than those found in the wild and are sprayed to ensure as even coverage as possible. Furthermore, at the short time scales under consideration here, it is unlikely that these highly abundant and uniformly distributed nematodes will be affected by spatial heterogeneities. Clearly, if control is considered over larger time scales, or if applications are strategically targeted (e.g., around host plants), it would be essential to consider the spatial distribution of pests to arrive at realistic application strategies.

We wish to emphasize that different species and strains of entomopathogenic nematodes are not the same. For instance, Heterorhabditis bacteriophora exhibits strong dispersal (cruising) tendencies and is very effective against deep-soil-dwelling species such as larvae of the Japanese beetle Popillia japonica, whereas the more sedentary nematode Steinernema carpocapsae is more effective against surface-dwelling pests (Georgis and Gaugler 1991; Lewis et al. 1993; Campbell et al. 1995). Clearly, these species, by exhibiting different search strategies, have different transmission rates under different conditions. In this article, we estimated $\beta$ only for the sciarid fly-Steinernema feltiae system. However, such an approach is likely to be more accurate than previous laboratory-based estimates where no account was made for abiotic factors such as soil structure, fluctuating temperature and moisture levels, or spatial interactions (Bohan and Hominick 1997; Westerman 1998). There is clearly an urgent need to assess transmission rates of entomopathogenic nematodes for different systems under a variety of conditions before complete control strategies can be formed.

This analysis has highlighted the potential use of entomopathogenic nematodes as biological control agents of invertebrate pests. Although the nematode-pest interaction may be highly unstable (Fenton et al. 2000), nematodes may be used to great effect as short-term control agents if the timing and levels of application can be appropriately chosen. This work presents a number of testable predictions concerning the success of control for different pest species for a range of different application methods. In addition, many of these findings can be directly applied to other potential biological control agents. Through this, we hope to have highlighted the need to consider the specific goals of the control program and the life-history 
parameters of the system under investigation before determining the optimum control strategy.

\section{Acknowledgments}

We would like to thank R. Gwynn of MicroBio Ltd., United Kingdom, for helpful discussions throughout this work and $\mathrm{H}$. McCallum and an anonymous referee for useful comments on the manuscript. The project is funded by a grant from the Natural Environment Research Council.

\section{APPENDIX A}

\section{The Stage-Structured Model}

The stage-structured model, which is a modified version of that of Briggs and Godfray (1995a) is

$$
\begin{aligned}
\frac{d L(t)}{d t} & =R(t)-M(t)-\delta_{\mathrm{L}} L(t)-\beta N(t) L(t), \\
\frac{d A(t)}{d t} & =M(t)-M\left(t-T_{\mathrm{A}}\right) \sigma_{\mathrm{A}}-\delta_{\mathrm{A}} A(t), \\
\frac{d N(t)}{d t} & =\Lambda \beta N\left(t-T_{\mathrm{I}}\right) L\left(t-T_{\mathrm{I}}\right)-\mu N(t),
\end{aligned}
$$

where the probability of surviving the adult stage $\sigma_{\mathrm{A}}=$ $\mathrm{e}^{-\delta_{\mathrm{A}} T_{\mathrm{A}}}$. The recruitment rate into the larval stage is given by $R(t)=\left(\rho / T_{\mathrm{AVE}}\right) A(t)$, where $\rho$ is the average lifetime fecundity and $T_{\mathrm{AVE}}=\left(1-\sigma_{\mathrm{A}}\right) / \delta_{\mathrm{A}}$ is the average duration of the adult host stage. The maturation rate out of the larval stage is given by

$$
M(t)=R\left(t-T_{\mathrm{L}}\right) \sigma_{\mathrm{L}}(t)
$$

where the probability of survival through the larval stage is given by

$$
\sigma_{\mathrm{L}(t)}=\exp \left(-\int_{t-T_{\mathrm{L}}}^{t} \beta N(x)+\delta_{\mathrm{L}} d x\right)
$$

\section{APPENDIX B}

\section{Analysis of the Preemptive Application of Nematodes}

The equation for the simplified model describing the preemptive application of nematodes is

$$
\frac{d X}{d t}=r X-\beta X N_{0} \mathrm{e}^{-\mu(t+d)}
$$

First, it can be seen that immediate suppression of the pest will occur if

$$
r<\beta N_{0} \mathrm{e}^{-\mu d}
$$

That is, the pest will go extinct if its growth rate at the time of invasion is less than the net rate of infection.

If equation (B2) is upheld, we can calculate the number of nematodes needed to be applied to suppress the pest population to below a predefined minimum threshold level $\left(X_{\mathrm{T}}\right)$ within a specified time, $\tau$. By integrating equation (B1), we obtain the following expression, relating the density of nematodes applied $\left(N_{0}\right)$ and the initial density of pests invading $\left(X_{0}\right)$ to the density of pests at time $t\left(X_{\mathrm{t}}\right)$ :

$$
\ln \left(X_{t}\right)=\ln \left(X_{0}\right)+r t+\frac{\beta N_{0} \mathrm{e}^{-\mu d}\left(\mathrm{e}^{-\mu t}-1\right)}{\mu} .
$$

By replacing $X_{t}$ with $X_{\mathrm{T}}$ and $t$ with $\tau$ in equation (B3) and rearranging, we obtain

$$
N_{0}=\frac{\mu \mathrm{e}^{\mu d}\left[r \tau-\ln \left(X_{\mathrm{T}} / X_{0}\right)\right]}{\beta\left(1-\mathrm{e}^{-\mu \tau}\right)},
$$

where $\tau$ represents the desired time in which to achieve suppression.

\section{APPENDIX C}

\section{Analysis of Constant Application of Nematodes}

As described in the main text, the equations for the model are

$$
\begin{aligned}
& \frac{d L(t)}{d t}=R(t)-M(t)-\delta_{\mathrm{L}} L(t)-\beta N(t) L(t), \\
& \frac{d A(t)}{d t}=M(t)-M\left(t-T_{\mathrm{A}}\right) \sigma_{\mathrm{A}}-\delta_{\mathrm{A}} A(t), \\
& \frac{d N(t)}{d t}=\Lambda \beta N\left(t-T_{\mathrm{I}}\right) L\left(t-T_{\mathrm{I}}\right)-\mu N(t)+\Gamma,
\end{aligned}
$$

where $\Gamma$ is the constant rate of nematode application. Although a full sensitivity analysis is beyond the scope of this article, we can determine some important behaviors of this model through analytical techniques. At equilibrium, the above equations are set equal to zero, and the state variables are $A(t)=A\left(t-T_{A}\right)=A^{*}, L(t)=L(t-$ 
$\left.T_{I}\right)=L^{*}$, and $N(t)=N\left(t-T_{I}\right)=N^{*}$. Hence, the equations become

$$
\begin{aligned}
& \frac{d L(t)}{d t}=R^{*}-M^{*}-\delta_{\mathrm{L}} L^{*}-\beta N^{*} L^{*}=0, \\
& \frac{d A(t)}{d t}=M^{*}-M^{*} \sigma_{\mathrm{A}}-\delta_{\mathrm{A}} A^{*}=0, \\
& \frac{d N(t)}{d t}=\Lambda \beta N^{*} L^{*}-\mu N^{*}+\Gamma=0 .
\end{aligned}
$$

The recruitment rate becomes $R^{*}=\rho A^{*} / T_{\mathrm{AVE}}$, and since $N^{*}$ is a constant at equilibrium, the maturation rate becomes

$$
M^{*}=R^{*} \mathrm{e}^{-T_{\mathrm{L}}\left(\beta N^{*}+\delta_{\mathrm{L}}\right)} .
$$

The above equations can be solved to produce the stable states $(0,0, \Gamma / \mu)$ and the coexistence equilibrium $\left(L^{*}\right.$, $A^{*}, N^{*}$ ), where

$$
\begin{aligned}
L^{*} & =\frac{1}{\Lambda \beta}\left\{\mu+\frac{\beta \Gamma T_{\mathrm{L}}}{\left[\ln (1 / \rho)+\delta_{\mathrm{L}} T_{\mathrm{L}}\right]}\right\}, \\
A^{*} & =\frac{\mathrm{L}^{*}\left(\delta_{\mathrm{L}}+\beta L^{*}\right)\left(1-\sigma_{\mathrm{A}}\right)}{\rho\left(1-\sigma_{\mathrm{L}}\right) \delta_{\mathrm{A}}}, \\
N^{*} & =-\frac{1}{T_{\mathrm{L}} \beta}\left[\ln (1 / \rho)+\delta_{\mathrm{L}} T_{\mathrm{L}}\right] .
\end{aligned}
$$

Inspection of the equations shows that, for $N^{*}$ to be biologically relevant, we need

$$
\rho \mathrm{e}^{-\delta_{\mathrm{L}} T_{\mathrm{L}}}>1
$$

The exponential term in condition (C1) represents mor $\rightarrow$ B tality through the larval stage in the absence of nematodes. Hence, for $\left(L^{*}, A^{*}, N^{*}\right)$ to be viable, the total number of eggs laid that survives to adulthood must exceed 1. For $L^{*}$ to be biologically relevant,

$$
\rho \mathrm{e}^{-\left[\left(\Gamma \beta T_{\mathrm{L}} / \mu\right)+\delta_{\mathrm{L}} T_{\mathrm{L}}\right]}>1 .
$$

The exponent in condition (C2) represents total mortality of larvae in the presence of nematodes. Once again, this means that the number of eggs that survive to adulthood has to exceed 1 for the equilibrium to be biologically relevant and for the pest to persist. Since the exponent ir $\rightarrow$ B condition (C2) is greater than that in condition (C1), condition (C2) is stricter, so that if fulfilled, condition (C1) is always true. In this case, the system sits at the stat $\rightarrow$ $\left(L^{*}, A^{*}, N^{*}\right)$ where coexistence of the pest and nematodes occurs. If condition (C2) is not fulfilled, the equilibrium point for the larval pest population becomes biologically impossible, and the pest eventually becomes extinct. This can occur if the nematode application rate is sufficiently high to make the left-hand side of condition $(\mathrm{C} 2)<1$. Hence, by rearranging condition (C2), we obtain the following expression for the threshold rate of application above which pests cannot survive, tipping the system from $\left(L^{*}, A^{*}, N^{*}\right)$ to $(0,0, \Gamma / \mu)$, thereby driving the pest to extinction:

$$
\Gamma_{\mathrm{T}}=\frac{\mu}{\beta T_{\mathrm{L}}}\left[\ln (\rho)-\delta_{\mathrm{L}} T_{\mathrm{L}}\right]
$$

\section{Literature Cited}

Anderson, R. M., and R. M. May. 1978. Regulation and stability of host-parasite population interactions. I. Regulatory processes. Journal of Animal Ecology 47: 219-247.

$\rightarrow \quad$. 1981. The population dynamics of microparasites and their invertebrate hosts. Philosophical Transactions of the Royal Society of London B, Biological Sciences 291:451-524.

$\rightarrow$ Bailey, D. J., and C. A. Gilligan. 1999. Dynamics of primary and secondary infection in take-all epidemics. Phytopathology 89:84-91.

$\rightarrow$ Begon, M., and R. G. Bowers. 1994. Host-host-pathogen models and microbial pest control: the effect of host self regulation. Journal of Theoretical Biology 169: 275-287.

$\rightarrow$ Begon, M., R. G. Bowers, N. Kadiankis, and D. E. Hodgkinson. 1992. Disease and community structure: the importance of host self-regulation in a host-host-pathogen model. American Naturalist 139:1131-1150.

Boag, B., R. Neilson, and S. C. Gordon. 1992. Distribution and prevalence of the entomopathogenic nematode Steinernema feltiae in Scotland. Annals of Applied Biology 121:355-360.

$\rightarrow$ Bohan, D. A., and W. M. Hominick. 1997. Long-term dynamics of infectiousness within the infective-stage pool of the entomopathogenic nematode Steinernema feltiae (site 76 strain) Filipjev. Parasitology 114:301-308.

$\rightarrow$ Bonsall, M. B., H. C. J. Godfray, C. J. Briggs, and M. P. Hassell. 1999. Does host self-regulation increase the likelihood of insect-pathogen population cycles? American Naturalist 153:228-235.

Briggs, C. J., and H. C. J. Godfray. 1995a. The dynamics of insect pathogen interactions in stage structured populations. American Naturalist 145:855-887.

$\rightarrow$. 1995b. Models of intermediate complexity in insect-pathogen interactions: population dynamics of the microsporidian pathogen, Nosema pyrausta, of the 
European corn borer, Ostrinia nubilalis. Parasitology 111:S71-S89.

$\rightarrow-$. 1996. The dynamics of insect-pathogen interac $\rightarrow$ tions in seasonal environments. Theoretical Population Biology 50:149-177.

Briggs, C. J., R. S. Hails, N. D. Barlow, and H. C. J. Godfray. 1995. The dynamics of insect-pathogen interactions $\rightarrow$ Pages 295-326 in B. T. Grenfell and A. P. Dobson, eds. Ecology of infectious diseases in natural populations. Cambridge University Press, Cambridge.

$\rightarrow$ Campbell, J. F., E. Lewis, F. Yoder, and R. Gaugler. $1995 \rightarrow$ Entomopathogenic nematode (Heterorhabditidae and Steinernematidae) seasonal population dynamics and impact on insect populations in turfgrass. Biological Control 5:598-606.

$\rightarrow$ Campbell, J. F., G. Orza, F. Yoder, E. Lewis, and R. Gaugler $\rightarrow$ 1998. Spatial and temporal distribution of endemic and released entomopathogenic nematode populations in turfgrass. Entomologia Experimentalis et Applicata $86 \rightarrow$ $1-11$.

$\rightarrow$ Comins, H. N., M. P. Hassell, and R. M. May. 1992. The spatial dynamics of host-parasitoid systems. Journal of Animal Ecology 61:735-748.

$\rightarrow$ D’Amico, V., J. S. Elkinton, G. Dwyer, J. P. Burand, and J. P. Buonaccorsi. 1996. Virus transmission in gypsy moths is not a simple mass action process. Ecology 77 201-206.

Downing, A. S. 1994. Effect of irrigation and spray volume on efficacy of entomopathogenic nematodes (Rhabditida: Heterorhabditidae) against white grubs (Coleop $\rightarrow$ tera: Scarabaediae). Journal of Economic Entomology 87:643-646.

$\rightarrow$ Dwyer, G., and J. S. Elkinton. 1993. Using simple models to predict virus epizootics in gypsy moth populations. Journal of Animal Ecology 62:1-11.

$\rightarrow$ Dwyer, G., J. S. Elkinton, and J. P. Buonaccorsi. 1997. Host heterogeneity in susceptibility and disease dynamics: tests of a mathematical model. American Naturalist 150: 685-707.

$\rightarrow$ Ehlers, R. U. 1996. Current and future use of nematodes in biocontrol: practice and commercial aspects with regard to regulatory policy issues. Biocontrol Science and Technology 6:303-316.

$\rightarrow$ Feaster, M. A., and D. C. Steinkraus. 1996. Inundative biological control of Helicoverpa zea (Lepidoptera: Noctuidae) with the entomopathogenic nematode Steinernema riobravis (Rhabditida: Steinernematidae). Biological Control 7:38-43.

$\rightarrow$ Fenton, A., R. A. Norman, J. P. Fairbairn, and P. J. Hudson. 2000. Modelling the efficacy of entomopathogenic nematodes in the regulation of invertebrate pests in glass. house crops. Journal of Applied Ecology 37:309-320.

Georgis, R., and R. Gaugler. 1991. Predictability in bio. logical control using entomopathogenic nematodes. Journal of Economic Entomology 84:713-720.

Godfray, H. C. J., and J. K. Waage. 1991. Predictive modeling in biological control: the mango mealy bug (Rastrococcus invadens) and its parasitoids. Journal of Applied Ecology 28:434-453.

Goulson, D., R. S. Hails, T. Williams, M. L. Hirst, S. D. Vasconcelos, B. M. Green, T. M. Carty, and J. S. Cory. 1995. Transmission dynamics of a virus in a stage-structured insect population. Ecology 76:392-401.

Grewal, P. S., and P. N. Richardson. 1993. Effects of application rates of Steinernema feltiae (Nematoda, Steinernematidae) on biological control of the mushroom fly Lycoriella auripila (Diptera, Sciaridae). Biocontrol Science and Technology 3:29-40.

Gubbins, S., and C. A. Gilligan. 1997. Persistence of hostparasite interactions in a disturbed environment. Journal of Theoretical Biology 188:241-258.

Hassell, M. P., and R. M. May. 1974. Aggregation of predators and insect parasites and its effect on stability. Journal of Animal Ecology 43:567-594.

Hastings, A. 1999. Outbreaks of insects: a dynamic approach. Pages 206-215 in B. A. Hawkins and H. V. Cornell, eds. Theoretical approaches to biological control. Cambridge University Press, Cambridge.

Hochberg, M. E., and J. K. Waage. 1991. A model for the biological control of Oryctes rhinoceros (Coleoptera, Scarabaeidae) by means of pathogens. Journal of Applied Ecology 28:514-531.

Hominick, W. M., and B. R. Briscoe. 1990. Survey of 15 sites over 28 months for entomopathogenic nematodes (Rhabditida, Steinernematidae). Parasitology 100: 289-294.

Hudson, P. J., and R. Norman. 1995. The role of entomopathogenic nematodes in regulating the abundance of pest species: a generalized model. Pages 52-57 in C. T. Griffin, R. L. Gwynn, and J. P. Mason, eds. Ecology and transmission strategies of entomopathogenic nematodes. COST Symposium 819. European Commission, Luxembourg.

Kareiva, P. 1990. Establishing a foothold for theory in biocontrol practice: using models to guide experimental design and release protocols. Pages 65-81 in R. R. Baker and P. E. Dunn, eds. New directions in biological control: alternatives for suppressing agricultural pests and diseases. Liss, New York.

Kaya, H. K. 1993. Contemporary issues in biological control with entomopathogenic nematodes. Food and Fertilizer Technology Center Extension Bulletin no. 375. Taipei, pp. 1-13.

Kaya, H. K., and R. Gaugler. 1993. Entomopathogenic nematodes. Annual Review of Entomology 38:181-206. 
Dynamically generated variability in plant-pathogen systems with biological control. Proceedings of the Royal Society of London B, Biological Sciences 263: 777-783.

Lewis, E. E., R. Gaugler, and R. Harrison. 1993. Response of cruiser and ambusher entomopathogenic nematodes (Steinernematidae) to host volatile cues. Canadian Jour nal of Zoology 71:765-769.

$\rightarrow$ May, R. M., and R. M. Anderson. 1978. Regulation and stability of host-parasite population interactions. II. Destabilizing processes. Journal of Animal Ecology 47: 249-267.

McCallum, H. 2000. Population parameters: estimation for ecological models. Blackwell Science, Oxford.

$\rightarrow$ Moerbeek, M., and F. van den Bosch. 1997. Insect-pathogen dynamics: stage-specific susceptibility and insect density dependence. Mathematical Biosciences 141: 115-148.

$\rightarrow$ Murdoch, W. W., and C. J. Briggs. 1996. Theory for biological control: recent developments. Ecology 77 2001-2013.

$\rightarrow$ Murdoch, W. W., J. Chesson, and P. L. Chesson. 1985. Biological control in theory and practice. American Naturalist 125:344-366.

$\rightarrow$ Murdoch, W. W., R. M. Nisbet, S. P. Blythe, W. S. C. Gurney, and J. D. Reeve. 1987. An invulnerable age class and stability in delay-differential parasitoid-host models. American Naturalist 129:263-282.

$\rightarrow$ Peters, A. 1996. The natural host range of Steinernema and Heterorhabditis spp. and their impact on insect populations. Biocontrol Science and Technology 6:389-402.

$\rightarrow$ Pye, A. E., and N. L. Pye. 1985. Different applications o the insect parasitic nematode, Neoaplectana carpocapsae to control the large pine weevil, Hylobius abietis. Nematologica 31:109-116.

$\rightarrow$ Rinker, D. L., T. H. A. Olthof, J. Dano, and G. Alm. 1995. Effects of entomopathogenic nematodes on control of a mushroom-infesting sciarid fly and on mushroom production. Biocontrol Science and Technology 5: 109-119.

$\rightarrow$ Rohani, P., and G. D. Ruxton. 1999. Dispersal-induced instabilities in host-parasitoid metapopulations. Theoretical Population Biology 55:23-36.

Scheepmaker, J. W. A., F. P. Geels, P. H. Smits, and L. Van Griensven. 1997. Control of the mushroom pests $L y$ coriella auripila (Diptera: Sciaridae) and Megaselia halterata (Diptera: Phoridae) by Steinernema feltiae (Nematoda: Steinernematidae) in field experiments. Annals of Applied Biology 131:359-368.

Smart, G. C. 1995. Entomopathogenic nematodes for the biological control of insects. Journal of Nematology 27: 529-534.

Smith, M. T., R. Georgis, A. P. Nyczepir, and R. W. Miller. 1993. Biological control of the pecan weevil, Curculio caryae (Coleoptera, Curculionidae), with entomopathogenic nematodes. Journal of Nematology 25:78-82.

Truscott, J. E., C. R. Webb, and C. A. Gilligan. 1997. Asymptotic analysis of an epidemic model with primary and secondary infection. Bulletin of Mathematical Biology 59:1101-1123.

$\rightarrow$ Truscott, J. E., C. A. Gilligan, and C. R. Webb. 2000. Quantitative analysis and model simplification of an epidemic model with primary and secondary infection. Bulletin of Mathematical Biology 62:377-393.

$\rightarrow$ Westerman, P. R. 1998. Penetration of the entomopathogenic nematode Heterorhabditis spp. into host insects at 9 and 20 degrees $\mathrm{C}$. Journal of Invertebrate Pathology 72:197-205.

$\rightarrow$ Wood, S. N., and M. B. Thomas. 1996. Space, time and persistence of virulent pathogens. Proceedings of the Royal Society of London B, Biological Sciences 263: 673-680. 